\title{
THE GRAVIMETRIC SEPARATION OF ZINC AND NICKEL.
}

\author{
By T. COCKBURN, F.I.C., A. D. GARDINER, AND J. W. BLACK.
}

ThE unsatisfactory results obtained by the commoner methods for the separation of zinc and nickel renders the analysis of German silver a matter of some difficulty.

For the purpose of our inquiry we selected a few of the better-known processes, omitting those involving the use of cyanides or fixed organic acids, whilst we directed special attention to obtaining zinc sulphide in a form in which it could be filtered-a desideratum which is frequently unattainable.

In order to obtain strictly comparable results, the same standard solutions of zinc and nickel and the same graduated glass apparatus were used throughout.

1. Precipitation of Zinc as Zinc Sulphide from an Acetic Acid Solution.-We found considerable difficulty in finding the correct conditions when employing this process. In many of our trials, either the precipitation of the zinc or the physical condition of the zinc sulphide proved unsatisfactory, but by adhering to the following details our best results were obtained :

To a faintly acid solution of the two metals a solution of sodium carbonate is added until a faint turbidity is produced, then 100 c.c. glacial acetic acid, the solution thoroughly cooled, and hydrogen sulphide passed into it for one hour at the rate of about 2 bubbles per second (cf. Lewis, J. Soc. Chem. Ind., 1909, 78, 587).

These conditions insure the production of zinc sulphide perfectly white in colour, and in a granular form permitting of easy filtration. The precipitated zinc sulphide is allowed to stand in the cold for some hours, and the clear supernatant liquid then completely decanted through a hardened Schleicher and Schüll No. 5 paper. The precipitate is washed with sulphuretted hydrogen water containing 2 per cent. ammonium acetate. After drying, the precipitate is separated from the paper, and ignition started at a low red heat, the temperature being gradually increased until a bright red heat is obtained. The duration of the ignition at a gradually rising temperature lasted one hour, when the zinc sulphide was entirely converted into zinc oxide.

The precipitates were tested for nickel by the exceedingly delicate reaction discovered by Tschugaeff (Chem. Zeit. Rep., 1905, 29, 247)-namely, the production of a dark scarlet nickel glyoxime when to the dilute hydrochloric acid solution of the precipitates, made slightly ammoniacal, was added an alcoholic solution of dimethylglyoxime :

TABLE I.

\begin{tabular}{l|c|c|c|c|c|c}
\hline $\begin{array}{c}\text { No. of } \\
\text { Experiment. }\end{array}$ & $\begin{array}{c}\text { Weight } \\
\text { of } \\
\text { Zinc taken. }\end{array}$ & $\begin{array}{c}\text { Weight } \\
\text { of } \\
\text { Nickel taken. }\end{array}$ & $\begin{array}{c}\text { No. of c.c. of } \\
\text { Glacial } \\
\text { Acetic Acid. }\end{array}$ & $\begin{array}{c}\text { Total } \\
\text { Volume of } \\
\text { Solution. }\end{array}$ & $\begin{array}{c}\text { Weight } \\
\text { of } \\
\text { Zinc found. }\end{array}$ & Difference. \\
\hline & $0 \cdot 1102$ & $0 \cdot 1934$ & 40 & 210 & $0 \cdot 1105$ & +0.0003 \\
2 & $0 \cdot 2203$ & $0 \cdot 1934$ & 50 & 260 & $0 \cdot 2211$ & $+0 \cdot 0008$ \\
3 & $0 \cdot 3672$ & $0 \cdot 1934$ & 100 & 260 & $0 \cdot 3675$ & +0.0003 \\
4 & 0.3672 & $0 \cdot 1934$ & 100 & 260 & $0 \cdot 3668$ & -0.0004 \\
5 & $0 \cdot 6793$ & $0 \cdot 1934$ & 100 & 260 & $0 \cdot 6791$ & -0.0002 \\
\hline
\end{tabular}


The results were negative in the instances shown in Table I., but we found that when using larger quantities of nickel there was a tendency for nickel to appear in the zinc precipitate, and consequently high results were obtained.

2. Precipitation of Zinc as Zinc Sulphide in Presence of Formic Acid (Waring's Method).-This process, which we prefer to the acetic acid method, was operated as described in Low's "Technical Methods of Ore Analysis," 5th ed., p. 294.

To the acid solution of zinc and nickel is added a drop of methyl orange, then from a pipette a very dilute solution of sodium hydroxide is run in until the pink colour barely but permanently changes to a light yellowish tint. Then sufficient formic acid (50 per cent. strength) is added drop by drop just to restore the permanent pink colour, and $\frac{1}{2}$ c.c. is added in addition. The solution is diluted to about 250 c.c. (or so that 100 c.c. contains not more than $0.2 \mathrm{grm}$. of metallic zinc), and heated to about $80^{\circ} \mathrm{C}$. Sulphuretted hydrogen is then passed through the solution under a slight pressure, and when the zinc has been completely precipitated the flask is disconnected, the precipitate allowed to subside, and the clear supernatant liquid passed through a hardened No. 5 filter or ordinary Swedish filter-paper, and the precipitate washed with hot water. As in the foregoing process, the zinc was weighed as zinc oxide:

TABLE II.

\begin{tabular}{l|c|c|c|c}
\hline $\begin{array}{c}\text { No. of } \\
\text { Experiment. }\end{array}$ & $\begin{array}{c}\text { Weight of } \\
\text { Zinc taken. }\end{array}$ & $\begin{array}{c}\text { Weight of } \\
\text { Nickel taken. }\end{array}$ & $\begin{array}{c}\text { Weight of } \\
\text { Zinc found. }\end{array}$ & Difference. \\
\hline & Grm. & Grm. & Grm. & Grm. \\
1 & 0.3672 & 0.0704 & 0.3684 & +0.0012 \\
2 & 0.1836 & 0.0704 & 0.1844 & +0.0008 \\
3 & 0.1836 & 0.1760 & 0.1827 & -0.0009 \\
4 & 0.0734 & 0.1760 & 0.0724 & -0.0010 \\
5 & 0.0734 & 0.3521 & 0.0730 & -0.0004 \\
6 & 0.2570 & 0.3521 & 0.2580 & +0.0010 \\
7 & 0.0734 & 0.7042 & 0.0769 & +0.0035 \\
\hline
\end{tabular}

The precipitates were tested for nickel by dimethylglyoxime. Positive results were obtained in Nos. 6 and 7. We found this method rapid and easily worked, whilst the separation, except in the case of No. 7, which contained a high proportion of nickel, was clean and sharp.

3. Precipitation of Zine as Zinc Sulphide from a Solution faintly Acidified with Hydrochloric Acid.-The results obtained by this method were unsatisfactory, and after an extended trial it was abandoned. As we anticipated, the main difficulty was to determine the quantity of free acid to employ, whilst the constantly increasing proportion of highly ionised free acid militates against accurate results being obtained.

4. Zimmermann's Process (Ann. d. Chem. und Pharm., 1879, 199, 3; 1880, 204, 226).--More was expected of this method, but notwithstanding the fact that we carried out the process exactly as described in Treadwell, vol. ii., p. 127, we were unable to obtain concordant results. 
With a view to estimating the nickel in the filtrates from the above, we reviewed the recent work of L. Dede (ANALxst, 1911, 36, 598), which promised to obviate the error arising from the well-known occlusion of alkali by nickel hydroxide. Dede employed potassium persulphate instead of bromine as the oxidising agent, and his results indicated an accuracy of $\pm 0.2 \mathrm{mgrm}$. on weighings up to $0.3 \mathrm{grm}$.

The results obtained by us did not conform to this degree of accuracy, notwithstanding the fact that the amount of alkali required in each test was calculated, and great care taken to employ only the smallest possible excess. We found that the precipitates and the nickel reduced therefrom invariably contained alkali, the amount of occluded matter being approximately proportional to the concentration of the nickel. The following results, which are typical of many obtained, plainly indicate this :

TABLE III.

\begin{tabular}{c|c|c|c}
\hline No. of Experiment. & Nickel taken. & Nickel fornd. & Difference. \\
\hline & Grm. & Grm. & Grm. \\
1 & 0.0704 & 0.0747 & +0.0043 \\
2 & 0.1408 & 0.1516 & +0.0108 \\
3 & 0.2464 & 0.2598 & +0.0134 \\
\hline
\end{tabular}

Separation of Nickel from Zinc.-In close connection with the foregoing work, we made an examination of the dimethylglyoxime method of separating nickel from zinc as detailed by O. Brunck (ANALYst, 1907, 32, 431). To the solution, first neutralised with dilute ammonia and rendered faintly acid with dilute hydrochloric acid, is added a 1 per cent. alcoholic solution of dimethylglyoxime in amount equivalent to seven times the quantity of nickel present. This was followed by the addition of a few c.c. of 10 per cent. sodium acetate solution. The solutions were maintained at the boiling-point for half an hour, filtered through a Gooch crucible having an asbestos felt, and washed with hot water. The precipitate was weighed as $\mathrm{Ni}\left(\mathrm{C}_{4} \mathrm{H}_{7} \mathrm{O}_{2} \mathrm{~N}_{2}\right)_{2}$. after drying at $110^{\circ} \mathrm{C}$.

TABLE IV.

\begin{tabular}{l|c|c|c|c}
\hline $\begin{array}{c}\text { No. of } \\
\text { Experiment. }\end{array}$ & $\begin{array}{c}\text { Weight of } \\
\text { Nickel taken. }\end{array}$ & $\begin{array}{c}\text { Weight of } \\
\text { Zinc taken. }\end{array}$ & $\begin{array}{c}\text { Weight of } \\
\text { Nickel found. }\end{array}$ & Difference. \\
\hline & Grm. & Grm. & Grm. & Grm. \\
1 & 0.0704 & - & 0.0714 & +0.0010 \\
2 & 0.0704 & 0.0734 & 0.0709 & +0.0005 \\
3 & 0.0704 & 0.3672 & 0.0712 & +0.0008 \\
4 & 0.0704 & 0.5508 & 0.0724 & +0.0020 \\
5 & 0.1408 & - & 0.1407 & -0.0001 \\
6 & 0.1408 & 0.1468 & 0.1408 & $\mp 0.0000$ \\
7 & 0.1408 & 0.3672 & 0.1410 & +0.0002 \\
\hline
\end{tabular}


The nickel glyoxime forms an extremely bulky precipitate, and we found that the concentration of $0.07 \mathrm{grm}$. of nickel per 250 c.c. was as high as desirable.

The process is applicable to the determination of nickel in the filtrates obtained from the separation of zinc after the removal of the sulphuretted hydrogen, formic acid, etc. The results obtained are shown in Table IV.

One of us is making an examination of the dicyan-diamidine method for the estimation of nickel with special reference to German silver, and will shortly publish his results.

Corporation Chemical Department, GLASGOW. 